\title{
Avaliação do uso de ventilação mínima em galpões avícolas e de sua influência no desempenho de aves de corte no período de inverno ${ }^{1}$
}

\section{Ricardo Brauer Vigoderis ${ }^{2}$, Marcelo Bastos Cordeiro $^{3}$, Ilda de Fátima Ferreira Tinôco ${ }^{3}$, Irene Menegali $^{3}$, Jalmir Pinheiro de Souza Júnior ${ }^{2}$, Mônica Calixto Ribeiro de Holanda ${ }^{2}$}

\author{
1 Projeto financiado pela FAPEMIG e pelo CNPq \\ 2 Universidade Federal Rural de Pernambuco, Unidade Acadêmica de Garanhuns - Av. Bom Pastor s/n, CEP: 55296-901 - Garanhuns - PE. \\ ${ }^{3}$ DEA/UFV - Campus Universitário, Viçosa - MG.
}

RESUMO - Objetivou-se com este trabalho avaliar um sistema de ventilação mínima ou de higiene e sua influência no conforto térmico, na qualidade do ar e no desempenho zootécnico de aves criadas durante o inverno. Foram utilizados dois galpões similares, cada um com 9.500 aves, da linhagem Cobb, durante um ciclo produtivo completo. Em um dos galpões, foi instalado um sistema de ventilação positiva que atendia à necessidade mínima de renovação de ar, composto por três ventiladores com vazão de $300 \mathrm{~m}^{3} / \mathrm{min}$, instalados no forro, paralelamente ao piso. O outro galpão foi considerado controle e não possuía sistema de ventilação. Houve diferença na temperatura e umidade relativa do ar nas duas primeiras semanas de vida das aves, sobretudo no sistema de ventilação mínima que apresentou as piores condições de conforto. As aves mantidas no galpão sem sistema de ventilação tiveram os melhores resultados de peso ao abate (com ventilação - 1,549 kg; e sem ventilação - 1,577 kg), conversão alimentar (com ventilação - 1,63 kg/kg; sem ventilação - 1,59 kg/kg) e eficiência produtiva (com ventilação - 285 e sem ventilação - 297). Houve diferença também na concentração de gases contaminantes, que foi menor no sistema com ventilação mínima. O sistema com ventilação mínima, da maneira como foi concebido no experimento, diminui significativamente a temperatura no interior do galpão avícola, comprometendo o conforto térmico e o desempenho animal. Apesar de o sistema com ventilação mínima resultar em menores concentrações de gases, nenhum dos sistemas promove concentração média de dióxido de carbono e monóxido de carbono prejudicial às aves.

Palavras-chave: ambiente térmico, avicultura de corte, qualidade do ar

\section{Evaluation of minimal ventilation and animal performance of broiler chickens in poultry houses during winter}

\begin{abstract}
The objective of this work was to evaluate a system of minimal or hygienic ventilation and its influence on thermal comfort, air quality and broiler zootechnical performance of poultries raised during the winter. Two similar sheds were used, with 9,500 Cobb broiler chickens per shed, during a complete productive cycle. In one of the sheds, a positive ventilation system that met minimal need of air renovation, composed by three fans with flow of $300 \mathrm{~m}^{3} / \mathrm{min}$, was installed on the ceiling parallel to the floor. The other shed was considered control and did not have a ventilation system. For the first two weeks of age of the broilers, temperature and air relative humidity differed, and the system with minimal ventilation showed the worst comfort conditions. Broilers kept in no ventilation system showed the best results for slaughter weight (with ventilation - 1.549; with no ventilation - $1.577 \mathrm{~kg}$ ), food conversion (with ventilation - $1.63 \mathrm{~kg} / \mathrm{kg}$ and with no ventilation - $1.59 \mathrm{~kg} / \mathrm{kg}$ ) and productive efficiency (with ventilation - 285 and without ventilation - 297). There were some differences for concentration of contaminant gases, which were lower in the system with minimal ventilation. The system with minimum ventilation, the way it was designed in the experiment, significantly decreases the temperature inside the poultry shed, compromising the thermal comfort and damaging animal performance. Although the system with minimum ventilation results in lower gas concentrations, none of systems promotes average concentration of carbon dioxide and carbon monoxide harmful to birds.
\end{abstract}

Key Words: air quality, broiler chicken production, thermal environmental

Recebido em 1/7/2008 e aprovado em 1/6/2009.

Correspondências devem ser enviadas para: vigoderis@yahoo.com.br 


\section{Introdução}

O controle do ambiente de criação animal é uma das principais necessidades para garantir o bem-estar das aves, visando maior produtividade e qualidade do produto final (Tinôco et al., 2004).

O ambiente interno onde os frangos estão inseridos é determinado por fatores físicos químicos e biológicos, que incluem o ambiente aéreo, a luz e os componentes construtivos (Tinôco, 2001). Alguns autores apontam que, entre os fatores ambientais, os térmicos são os que afetam diretamente as aves, pois comprometem sua função vital mais importante, que é a manutenção de sua homeotermia (Welker, 2008; Barbosa Filho, 2009). No entanto, deve-se dar atenção também à qualidade do ar no interior dos galpões.

As atividades agropecuárias são fontes significantes de poluentes aéreos (Brink et al., 2001; Kocaman et al., 2005), e a depreciação da qualidade do ar afeta a saúde e o bem-estar dos animais e dos tratadores e constitui um risco para a qualidade ambiental (Nääs et al., 2007). Os contaminantes podem carregar patógenos específicos, ou alterar sua virulência, afetando o crescimento das aves (Wathes, 1999).

Diante dos problemas ocasionados pela má qualidade do ar, torna-se necessário o manejo adequado da ventilação mínima, natural ou mecânica, visando evitar concentrações de gases indesejáveis dentro do aviário; entretanto, devese atentar à perda de calor, principalmente na fase inicial de vida das aves.

O aquecimento é fundamental no início da vida e dele depende o bom desenvolvimento das aves (Tinôco, 2001). O rápido crescimento das aves e o ambiente frio são considerados os principais fatores predisponentes ao desenvolvimento da síndrome ascítica (Wideman \& Tackett, 2000).

Em períodos frios e nas fases iniciais dos animais, é necessário evitar também a perda de calor para fora do aviário, por meio do maior controle das aberturas, em detrimento muitas vezes da renovação do ar interno. Compatibilizar esses dois fatores tem sido um desafio para a indústria avícola, que também tem sido pressionada frente às novas exigências internacionais de bem-estar animal.

Diante do exposto, conduziu-se esta pesquisa com o objetivo de avaliar um sistema de ventilação mínima e sua influência no conforto térmico, na qualidade do ar e no desempenho de aves criadas em galpões avícolas durante o inverno.

\section{Material e Métodos}

A pesquisa foi realizada com frangos de corte, no período de julho a agosto de 2004, na cidade de Videira, oeste de Santa Catarina, latitude de $27^{\circ} 00^{\prime}$ sul, longitude $51^{\circ} 09^{\prime}$ oeste e $750 \mathrm{~m}$ de altitude, cujo clima é temperado úmido, com temperatura média anual de 16 a $17^{\circ} \mathrm{C}$ e tipo climático $\mathrm{Cfb}$ - temperado (mesotérmico úmido e verão ameno), segundo classificação de Köppen.

No experimento foram utilizados dois galpões avícolas comerciais no padrão adotado pela empresa integradora, com dimensões idênticas $(12,0 \times 50,0 \times 3,0 \mathrm{~m})$, de mesmas características construtivas, e ambos na orientação lesteoeste. Os galpões possuíam forros de polietileno, posicionados a 3,0 $\mathrm{m}$ de altura e laterais teladas protegidas por duplo cortinado de poliuretano. A cobertura era de telhas de cerâmica, com inclinação de $30 \%$ e beiral de 0,50 m. As cortinas laterais foram mantidas fechadas durante o período de aquecimento devido às baixas temperaturas externas. A partir da terceira semana, as cortinas foram manejadas para manutenção da temperatura interna.

Foram utilizadas 9.500 aves de corte por galpão, linhagem Cobb, pertencentes às mesmas matrizes de mesmo lote e idade, originadas do incubatório da integradora. A lotação de aves foi de 15,8 aves $/ \mathrm{m}^{2}$ eas aves foram abatidas aos 32 dias de idade.

Os galpões foram equipados com o mesmo número de linhas de comedouros automáticos Aviflex e de bebedouros do tipo nippli, sendo ambos da marca Agromarau, distribuídos uniformemente em toda a área, conforme densidade sugerida pela empresa integradora. No período inicial, correspondente às duas primeiras semanas de vida, as aves foram confinadas numa área correspondente a 1/3 do total do galpão. Esse espaço, denominado pinteiro, foi protegido com cortina plástica para reduzir o espaço a ser aquecido. O sistema de aquecimento adotado para os dois galpões foi o de campânulas a gás para as duas primeiras semanas de vida das aves.

Cada galpão avícola foi considerado um tratamento: com ventilação mínima e sem ventilação.

O galpão com sistema de ventilação mínima foi dotado de três ventiladores com vazão de $300 \mathrm{~m}^{3} / \mathrm{min}$, instalados no forro, paralelamente ao piso, insuflando ar para o galpão. $\mathrm{O}$ sistema de controle foi programado para acionar e manter os ventiladores em funcionamento durante 30 segundos a cada ciclo de 2 minutos durante as duas primeiras semanas e a partir da terceira semana somente nos horários em que as cortinas laterais estavam fechadas, quando a programação era de 30 segundos de funcionamento a cada 10 minutos. 
Para caracterizar o ambiente térmico foram tomadas as medidas de temperatura e umidade relativa do ar em três pontos de cada galpão. Cada galpão foi dividido em três áreas de dimensões idênticas e cada sensor foi instalado no centro geométrico de cada área. Os registros foram realizados a uma altura compatível com a zona de ocupação dos pintinhos, a 10,0 cm da cama, em intervalos de 15 minutos, durante todo o período experimental. Foram utilizados dataloggers T/HR da marca Testo, modelo H1.

O monitoramento instantâneo da concentração de gases, amônia $\left(\mathrm{NH}_{3}\right)$, monóxido de carbono (CO) e dióxido de carbono $\left(\mathrm{CO}_{2}\right)$, em ppm, foram obtidas diariamente às $9 \mathrm{~h}$ e às $14 \mathrm{~h}$, nos dois galpões, durante todo o período experimental.

Para registro da concentração de $\mathrm{CO}_{2}$, foi utilizado sensor da marca Testo, modelo 535, de princípio infravermelho, com resolução de 1 ppm e acurácia de \pm 50 ppm que detecta a concentração instantânea numa faixa de medição de 0 a 10.000 ppm. Para o registro de monóxido de carbono, foi utilizado sensor da marca Testo, modelo 315-2, de princípio eletroquímico, com resolução de 1 ppm e acurácia de \pm 1 ppm que detecta a concentração instantânea numa faixa de 0 a 100 ppm. E para as concentrações de amônia, foi utilizado um sensor da marca Quest, modelo Safecheck 100, de princípio eletroquímico, com resolução de 1 ppm e acurácia de \pm 1 ppm que detecta a concentração instantânea numa faixa de medição de 0 a 100 ppm, cuja célula foi substituída e calibrada por uma empresa cadastrada pelo Instituto Nacional de Metrologia, Normalização e Qualidade Industrial (Inmetro).

As variáveis utilizadas para determinação do desempenho zootécnico foram ganho de peso e consumo de ração aos 7, 14, 21 e 28 dias, peso ao abate, conversão alimentar (obtida a partir do consumo de ração dividido pelo ganho de peso), mortalidade (\%) e índice de eficiência produtiva, que é obtido pelo peso médio do lote no dia da retirada, multiplicado pela viabilidade criatória, que é obtida pela subtração de 100, menos a mortalidade. Todo esse numerador é dividido pela idade do lote na retirada, multiplicado pela conversão alimentar e, após a divisão, é multiplicado por cem e calculado aos 32 dias de idade das aves.

Para o estudo das variáveis ambientais e qualidade do ar, o experimento foi disposto em esquema de parcelas subdivididas, contendo nas parcelas os tratamentos (com ventilação; e sem ventilação) e nas subparcelas os horários do delineamento em blocos casualizados.

Para o estudo do desempenho animal os sistemas com e sem ventilação foram dispostos num esquema de parcelas subdivididas, contendo os tratamentos nas parcelas e nas subparcelas as semanas de observação.

\section{Resultados e Discussão}

Nas três primeiras semanas de vida das aves, a temperatura do ar $\left({ }^{\circ} \mathrm{C}\right)$ diferiu $(\mathrm{P}<0,05)$ entre os sistemas de criação e foi menor no galpão com ventilação. Entretanto, em nenhum dos galpões foi possível manter a temperatura dentro da faixa de conforto térmico de 32 a $34^{\circ} \mathrm{C}$ recomendada por Macari et al (2004) e Ferreira (2005) para as aves de corte na primeira semana de vida (Figura 1A).

Na segunda semana, nos dois galpões a temperatura na faixa de conforto das aves na maioria dos horários observados, de modo que, nos horários considerados críticos para baixas temperaturas (das 2 às $6 \mathrm{~h}$ ), foi detectada, no galpão com ventilação, temperatura de até $2,2^{\circ} \mathrm{C}$ abaixo da temperatura de $28^{\circ} \mathrm{C}$, enquanto, no galpão sem ventilação, foi detectada temperatura $0,6^{\circ} \mathrm{C}$ abaixo da temperatura ideal (Figura 1B). Para a segunda semana de vida, a faixa de conforto térmico recomendada situa-se entre 28 e $32^{\circ} \mathrm{C}$, segundo Macari et al. (2004) e Ferreira (2005).

Na terceira semana de vida das aves, a temperatura no interior dos galpões oscilou, na maioria dos horários, acima da faixa de recomendação para o bem-estar térmico das aves que, segundo Tinôco (2001), Ferreira (2005) e Medeiros et al. (2005), situa entre 26 e $28^{\circ} \mathrm{C}$. No galpão com ventilação, foi mantida a temperatura acima da faixa ideal durante 12,5 horas e 5,5 horas abaixo da temperatura ideal. Já no galpão sem ventilação, foi mantida a temperatura acima da faixa ideal durante 13,0 horas e abaixo da temperatura ideal 3,25 horas (Figura 1C). Esses dados indicam que o sistema com ventilação mínima interferiu no ambiente térmico do galpão avícola, o que não é recomendável, pois a função deste sistema é somente manter a qualidade do ar em condições adequadas para as aves (Tinôco et al., 2004).

Na quarta semana (Figura 1D), o sistema de ventilação mínima foi acionado somente durante o período noturno, quando as cortinas laterais eram fechadas. Mesmo assim não foi suficiente para diferenciar $(\mathrm{P}<0,05)$ do sistema sem ventilação.

Na primeira e segunda semanas de vida das aves, à umidade relativa do ar $(\%)$, diferiu $(\mathrm{P}<0,05)$ entre os dois sistemas nos horários mais frios (das 20 às $10 \mathrm{~h}$ ), foi maior no sistema com ventilação (Figuras 2A e 2B). No entanto, na primeira semana, nestes horários, os valores de umidade relativa estiveram na faixa de conforto recomendada para aves de corte, que, segundo Tinôco (2001) e Medeiros et al (2005), situa-se entre 50 e $70 \%$. Na segunda semana, o sistema com ventilação apresentou valores acima (78,1\% do período) da faixa recomendada na maioria dos horários. Segundo Tinôco et al. (2004), com valores 
muito altos de umidade relativa, as aves ficam mais sensíveis ao estresse térmico.

Na terceira e quarta semanas de vida das aves (Figuras 2C e 2D), a umidade relativa esteve, na maioria dos horários, dentro da faixa de conforto e somente nos horários mais quentes do dia (das 14 às 16h30) esteve abaixo de 50\%.

As concentrações de $\mathrm{NH}_{3}$, $\mathrm{CO}$ e $\mathrm{CO}_{2}$ diferiram entre os sistemas e foram menores no galpão com ventilação (Tabela 1).

No galpão sem ventilação, foram detectadas concentrações de amônia valores superiores aos limites aceitáveis para aves de corte, que, segundo Wathes et al. (1998), são de 25 ppm. Segundo Kocaman et al. (2006), a variação na concentração de amônia é influenciada pela temperatura, umidade, densidade animal e taxa de ventilação. De acordo com Reece et al. (1980), a concen- tração de amônia deve ser inferior a 25 ppm até a quarta semana de criação. Acima da quarta semana não pode exceder 50 ppm. Segundo Hernandes et al. (2002), é necessário controle rigoroso da amônia no ar dos galpões avícolas, principalmente em densidades elevadas e no período final de criação.

Tabela 1 - Concentração de monóxido de carbono (CO), dióxido de carbono $\left(\mathrm{CO}_{2}\right)$ e amônia $\left(\mathrm{NH}_{3}\right)$ nos sistemas com e sem ventilação

\begin{tabular}{lcc}
\hline Gás $(\mathrm{ppm})$ & \multicolumn{2}{c}{ Sistemas de ventilação } \\
\hline & Com ventilação & Sem ventilação \\
\cline { 2 - 3 } CO & $3,3 \mathrm{~b}$ & $6,0 \mathrm{a}$ \\
$\mathrm{CO} 2$ & $1427,3 \mathrm{~b}$ & $1527,7 \mathrm{a}$ \\
$\mathrm{NH} 3$ & $23,2 \mathrm{~b}$ & $29,3 \mathrm{a}$ \\
\hline
\end{tabular}

Médias seguidas das mesmas letras nas linhas não apresentaram diferença $(\mathrm{P}>0,05)$ pelo teste Tukey.

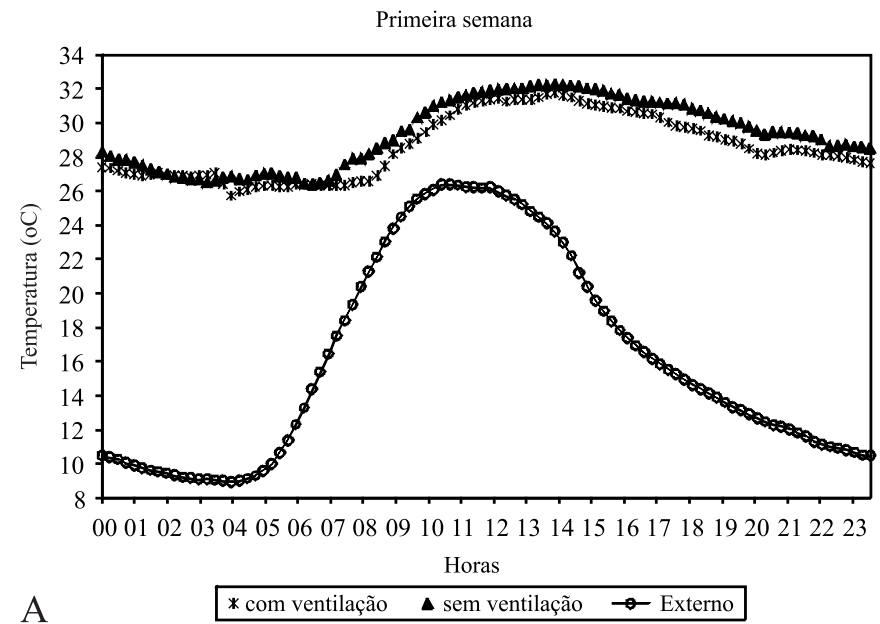

A

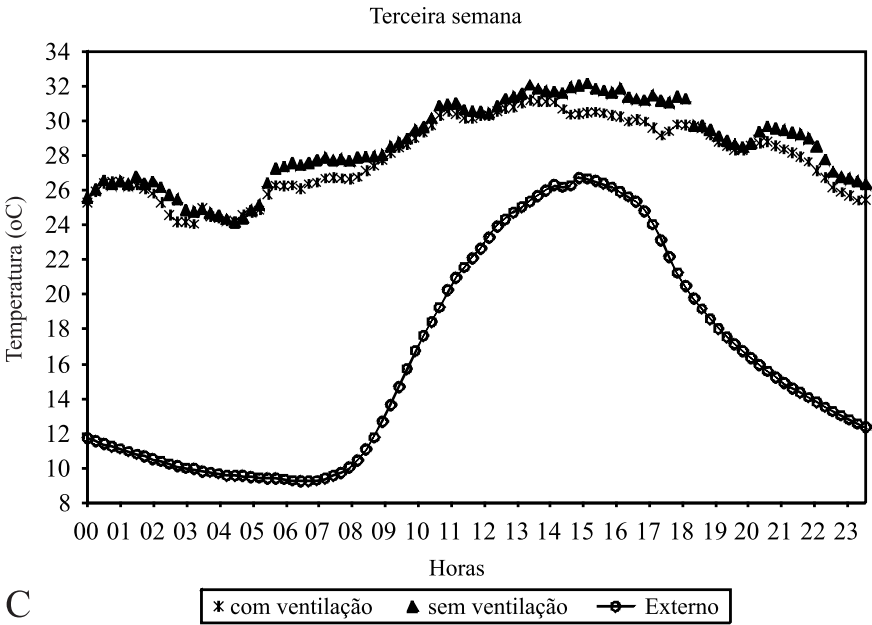

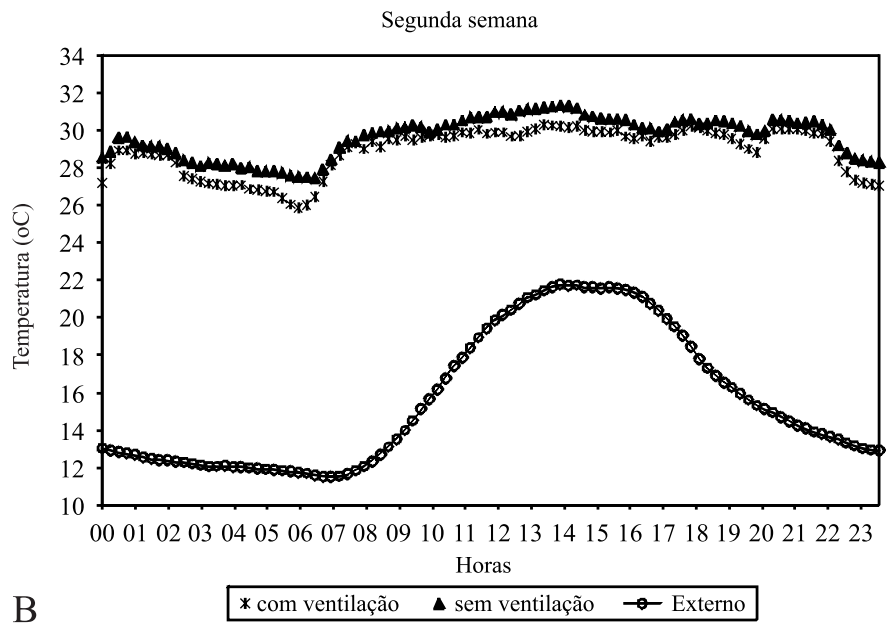

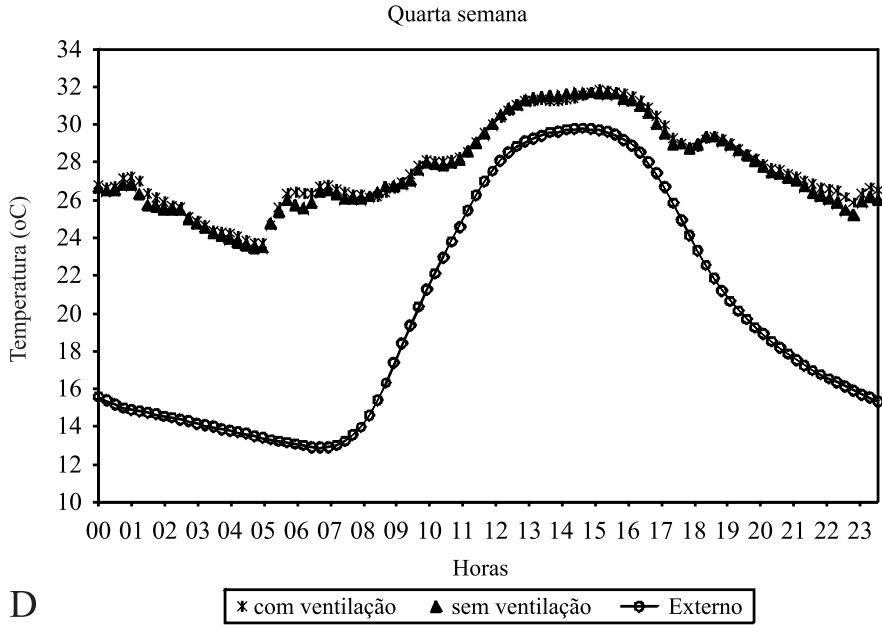

Figura 1 - Temperatura do $\operatorname{ar}\left({ }^{\circ} \mathrm{C}\right)$ em galpões com e sem sistema de ventilação mínima na primeira $(A)$, segunda (B), terceira (C) e quarta (D) semanas. 
De acordo com os valores críticos médios de concentrações de $\mathrm{CO}_{2}$ para aves de corte de 3.000 ppm (Wathes, 1999), nenhum dos sistemas de ventilação avaliados atingiu valores prejudiciais às aves.

Nenhum sistema de ventilação atingiu valores de CO superiores ao recomendado por Wathes (1999) e Cigr (1992), de 10 ppm para exposição contínua dos animais nas instalações. Segundo Nääs et al. (2007), o CO, resultante da queima incompleta do gás GLP, pode afetar os sistemas cardiovascular, nervoso central e reprodutivo das aves quando presente em altas concentrações no ar. É importante criar condições de renovação de ar no interior dos galpões, mas não em detrimento do aquecimento dos pintainhos na fase inicial de criação (Tinoco et al., 2004).

Houve diferença $(\mathrm{P}<0,05)$ entre os sistemas de ventilação para conversão alimentar e eficiência produtiva, sendo que no galpão sem ventilação as aves apresentaram melhor desempenho (Tabela 2).

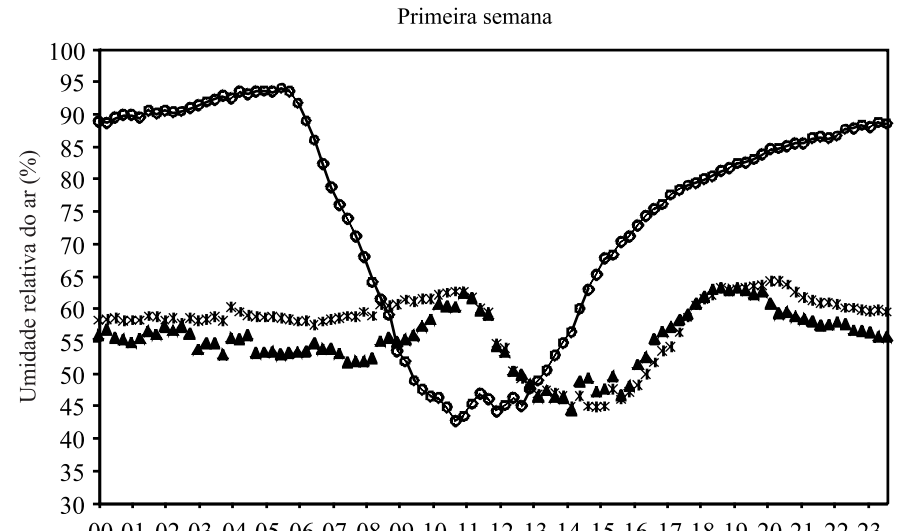

000102030405060708091011121314151617181920212223

A

$$
\text { * com ventilação } \Delta \text { sem ventilação } \rightarrow \text { Externo }
$$

Terceira semana
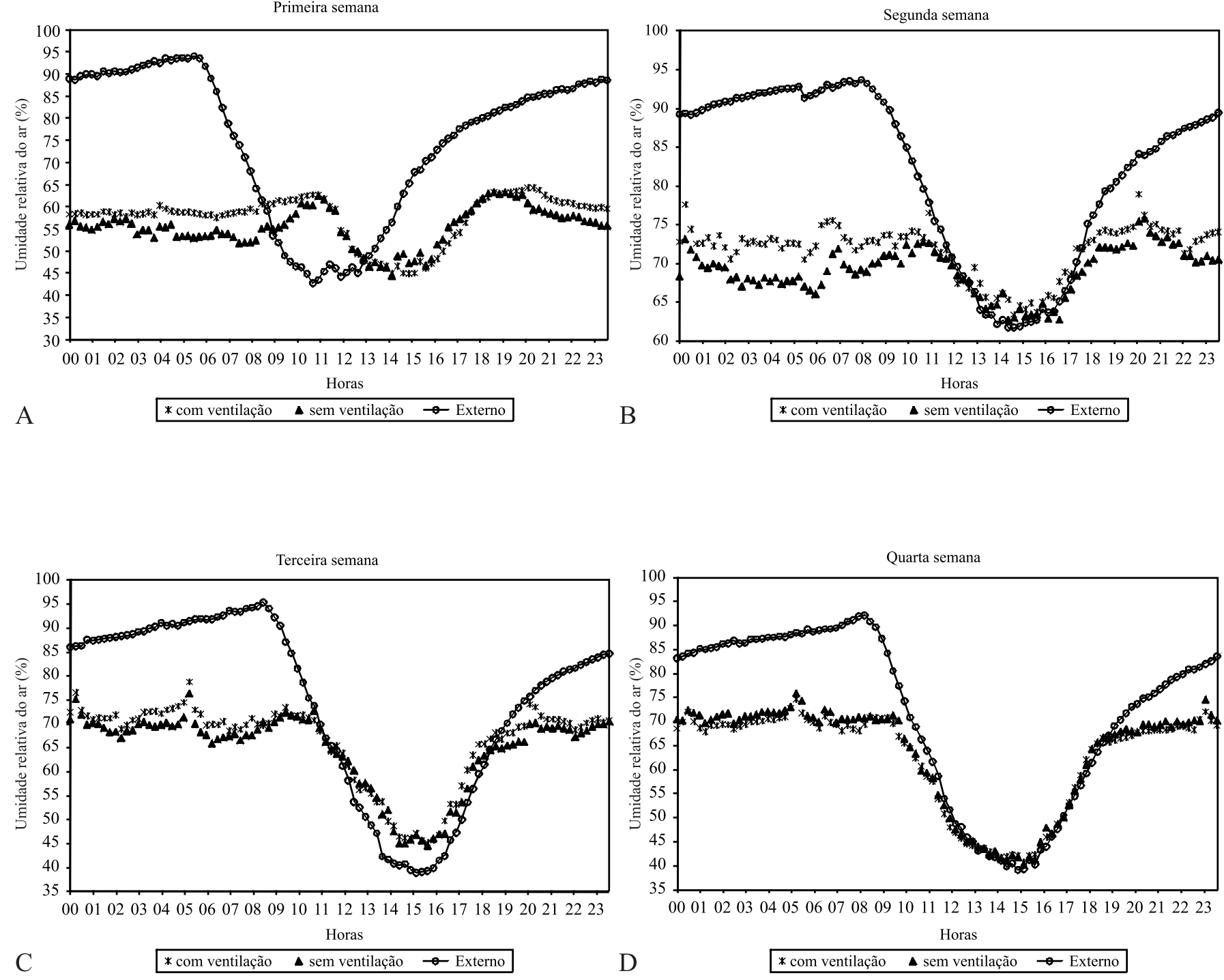

Figura 2 - Umidade relativa do ar (\%) nos galpões com e sem sistema de ventilação mínima na primeira (A), segunda (B), terceira (C) e

\footnotetext{
quarta (D) semanas de vida das aves.
} 
Tabela 2 - Peso ao abate (kg), conversão alimentar (kg/kg) e índice de eficiência produtiva e mortalidade (\%) de frangos de corte criados em sistemas de ventilação

\begin{tabular}{lcc}
\hline & \multicolumn{2}{c}{ Sistemas de ventilação } \\
\cline { 2 - 3 } Característica de desempenho & Com ventilação & Sem ventilação \\
\cline { 2 - 3 } Peso ao abate $(\mathrm{kg})$ & $1,549 \mathrm{a}$ & $1,577 \mathrm{a}$ \\
Conversão alimentar $(\mathrm{kg} / \mathrm{kg})$ & $1,63 \mathrm{a}$ & $1,59 \mathrm{~b}$ \\
Eficiência produtiva & $285 \mathrm{~b}$ & $297 \mathrm{a}$ \\
Mortalidade (\%) & $1,25 \mathrm{a}$ & $1,5 \mathrm{a}$ \\
\hline
\end{tabular}

Médias seguidas das mesmas letras nas linhas não apresentaram diferença $(\mathrm{P}>0,05)$ pelo teste Tukey.

Os piores resultados de desempenho das aves do galpão com ventilação devem-se provavelmente ao pior acondicionamento térmico. As baixas temperaturas do inverno fizeram com que os sistemas de aquecimento adotados não fossem eficientes para o aquecimento satisfatório das aves, entretanto, no galpão com ventilação, essa condição foi agravada pela ventilação, que descaracterizou sua função de apenas renovar o ar e passou a influenciar diretamente na condição térmica do galpão.

Não houve diferença na mortalidade, entretanto uma taxa de até 3\% em frangos de corte pode ser considerada normal, mas deve ser um sinal de alerta quando ultrapassar estes valores (Englert, 1998).

\section{Conclusões}

O sistema com ventilação mínima, da maneira como foi concebido no experimento, diminui significativamente a temperatura no interior do galpão avícola, comprometendo o conforto térmico e prejudicando o desempenho animal, avaliado por meio da conversão alimentar, do peso de abate e da eficiência produtiva. Apesar de o sistema com ventilação mínima resultar em menores concentrações de gases, nenhum dos sistemas promoveu concentração média de dióxido e monóxido de carbono prejudicial às aves. A utilização do sistema de ventilação mínima resulta em concentrações médias de amônia inferiores ao limite mínimo sugerido pela literatura para o interior de galpões avícolas.

\section{Referências}

BARBOSA FILHO, J.A.D.; VIEIRA, F.M.C.; SILVA, I.J.O. et al. Transporte de frangos: caracterização do microclima na carga durante o inverno. Revista Brasileira de Zootecnia, v.38, n.12, p2442-2446, 2009 .
BRINK, C.; KROEZE, C.; KILMONT, Z. Ammonia abatement and its impact on emissions of nitrous oxide and methane in Europe. Atmospheric Environment, v.35, p.6299-6312, 2001.

COMMISSION INTERNATIONALE DU GÉNIE RURAL - CIGR. Climatization of animal houses. Final report of working group. Aberdeen: Scottish Farm Buildings Investigation Unit, 1992. 58p.

ENGLERT, S.I. Avicultura: tudo sobre raças, manejo e nutrição. 7.ed. Guaíba: Agropecuária, 1998. 238p.

FERREIRA, R.A. Maior produção com melhor ambiente para aves, suínos e bovinos. Viçosa, MG: Aprenda Fácil, 2005. 371p.

HERNANDES, R.; CAZETTA, J.O.; MORAES, V.M.B. Frações nitrogenadas, glicídicas e amônia liberada pela cama de frango de corte em diferentes densidades e tempos de confinamento. Revista Brasileira de Zootecnia, v.31, n.4, p.1795-1802, 2002.

KOCAMAN, B.; ESENBUGA, N.; YILDIZ, A. et al. Effect of environmental conditions in poultry houses on the performance of laying hens. International Journal of Poultry Science, v.5, n.1, p.26-30, 2006.

KOCAMAN, B.; YAGANOGLU, A.V.; YANAR, M. Combination of fan ventilation system and spraying of oil-water mixture on the levels of dust and gases in caged layer facilities in Eastern Turkey. Journal Applied Animal Research, v.27, p.109-111, 2005.

MACARI, M.; FURLAN, R.L.; MAIORKA, A. Aspectos fisiológicos e de manejo para manutenção da homeostase térmica e controle de síndromes metabólicas. In: MENDES, A.A.; NÄÄS, I.A.; MACARI, M. (Eds.) Produção de frangos de corte. Campinas: FACTA, 2004. p.137-155.

MEDEIROS, M.M.; BAETA, F.C.; OLIVEIRA, R.F.M. et al. Efeitos da temperatura, umidade relativa e velocidade do ar em frangos de corte. Engenharia na Agricultura, v.13, n.4, p.277-286, 2005.

NÄÄS, I.A.; MIRAGLIOTTA, M.Y.; BARACHO, M.S. et al. Ambiência aérea em alojamento de frangos de corte: poeira e gases. Engenharia Agrícola, v.27, n.2, p.326-335, 2007.

REECE, F.N.; LOTT, B.D.; DEATON, J.W. Ammonia in the atmosphere during brooding affects performance of broiler chickens. Poultry Science, v.59, p.486, 1980.

TINÔCO, I.F.F.; FIGUEIREDO, J.L.A.; SANTOS, R.C. et al. Placas porosas utilizadas em sistemas de resfriamento evaporativo. Revista Engenharia na Agricultura, v.12, n.1, p.17-23, 2004.

TINÔCO, I.F.F. Avicultura industrial: novos conceitos de materiais, concepções e técnicas construtivas disponíveis para galpões avícolas brasileiros. Revista Brasileira de Ciência Avícola, v.3, n.1, p.1-26, 2001

WIDEMAN, R.F.; TACKETT, C.D. Cardio-pulmonary function in broilers reared at warm or cool temperatures: effect of acute inhalation of $100 \%$ oxygen. Poultry Science, v.79, n.2, p.257-264, 2000.

WATHES, C.M. Strive for clean air in your poultry house. World Poultry Science Journal, v.15, n.3, p.17-19, 1999.

WATHES, C.M.; PHILLIPS, V.R.; HOLDEN, M.R. et al. Emissions of aerial pollutants in livestock buildings in Northern Europe: overview of a multinational project. Journal of Agricultural Engineering Research, v.70, n.1, p.3-9, 1998.

WELKER, J.S.; ROSA, A.P.; MOURA, D.J. et al. Temperatura corporal de frangos de corte em diferentes sistemas de climatização. Revista Brasileira de Zootecnia, v.37, n.8, p.1463-1467, 2008 